\title{
Wenn die Blätter treiben
}

Erhard Taverna

erhard.taverna[at]saez.ch
«- wird wachen, lesen, lange Briefe schreiben und wird in den Alleen hin und her - unruhig wandern, wenn die Blätter treiben». Mit dem Schatten auf den Sonnenuhren, so Rainer Maria Rilke in seinem Herbstgedicht, kommt die Zeit des Lesens. Zum Beispiel einen Krimi von Robert Vieli oder von Paul Wittwer, oder Kurzgeschichten von Adolf Jens Koemeda oder Halbfiktionales über den Erfinder des Ballonkatheters von Alfred Bollinger. Es lohnt sich, in diese Welten einzutauchen, sie überraschen, unterhalten und bereichern Leserinnen und Leser.

\section{«Der Duft des Verbrechens» von Robert Vieli} Der Altmeister aus Chur erzählt eine spannende und wie immer auch erheiternde Mordgeschichte, in der ein ausdauernder Kommissar einen arroganten Zahnarzt in die Enge treibt. Mit bühnenreifen Dialogen inszeniert der Autor eine Kriminalkomödie, in der ein unermüdlicher Ermittler, allen Hindernissen zum Trotz, sein Ziel erreicht, oder zumindest fast. Die Handlung ist logisch, das Personal stimmig, die perfekt konstruierten Auftritte fügen sich nahtlos zu einer rasanten Erzählung, die von der ersten bis zur letzten Seite gute Unterhaltung bietet. Eigentlich müssten auch die Macher der Studios am Leutschenbach herausfinden, dass hier der Stoff für einen guten Tatort-Film direkt vor ihrer Nase liegt.

\section{«Widerwasser» von Paul Wittwer}

Mit seinem dritten Kriminalroman beweist der Allgemeinmediziner von Burgdorf erneut sein Können. Im Mittelpunkt steht ein Kollege, dem in einer tiefen Lebenskrise der Zufall eine einmalige Chance bietet. Ein gekündigter Job, eine Scheidung und über allem ein zäher Herbstnebel, wer würde da nicht gerne seine Identität wechseln und mit einem Koffer voller Geld nach Süden fahren? Dumm nur, dass der Tote unter Berns Kornhausbrücke eine dunkle Vergangenheit hat, die den sorglosen Doppelgänger sehr schnell bedrohlich einholt. Die Schauplätze in Bern und Süditalien verknüpft Paul Wittwer geschickt zu einem abwechslungsreichen Komplott, den ein espressoliebender Kommissar mühevoll zu entwirren versucht. Treffende Bilder, originelle Figuren und ein verwegener Plot machen die Lektüre zu einem garantierten Lesevergnügen.

\section{«Der Normalsprecher» \\ von Adolf Jens Koemeda}

Den Autor kennen viele von verschiedenen Kurzgeschichten in der Schweizerischen Ärztezeitung. Einige der 14 Erzählungen sind bekannt, die meisten wurden neu für die vorliegende Anthologie geschrieben. Bei aller Vielfalt geht es darin immer um subtil geschilderte Lebenskrisen, die von den Hauptdarstellern meist ungeliebte Entscheidungen

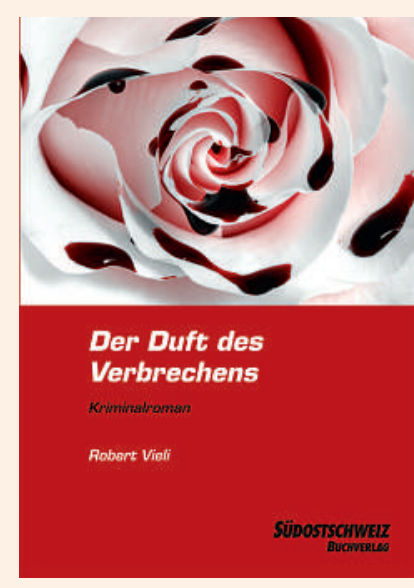

Robert Vieli

Der Duft des Verbrechens

Glarus: Südostschweiz Buchverlag; 2011

318 Seiten. $29.90 \mathrm{CHF}$ ISBN 978-3-3905688-80-1

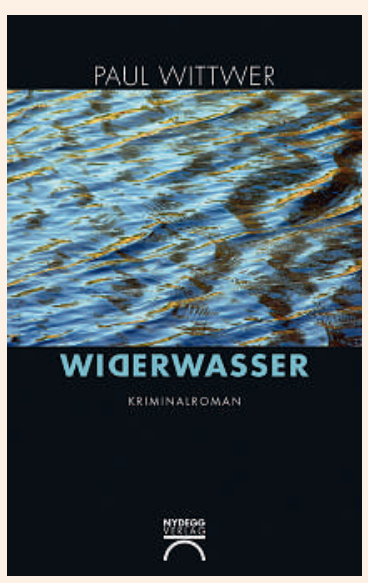

Paul Wittwer

Widerwasser

Bern: Nydegg; 2011

400 Seiten. $39 \mathrm{CHF}$

ISBN 978-3-90596-102-7

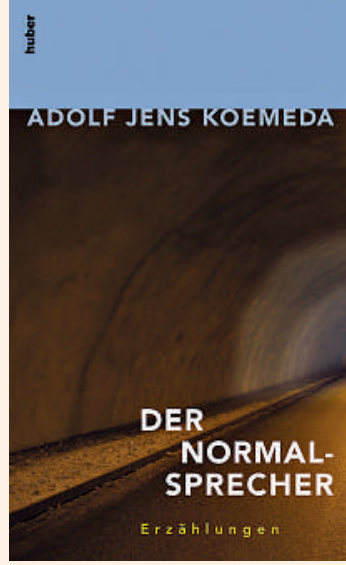

Adolf Jens Koemeda Der Normalsprecher

Zürich: Huber; 2011

200 Seiten 29.90 CHF

ISBN 978-3-71931-573-3

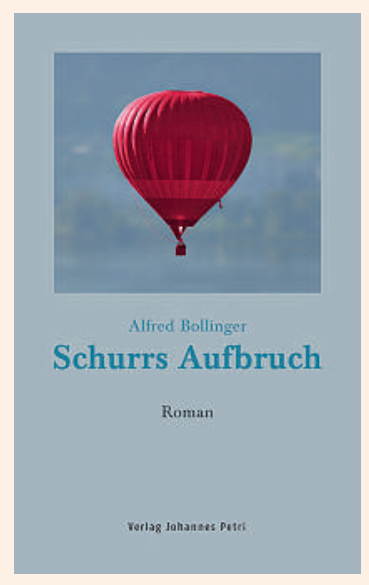

Alfred Bollinger Schurrs Aufbruch

Basel: Johannes Petri; 2011 289 Seiten. $28 \mathrm{CHF}$ ISBN 978-3-03784-009-2 
erfordern. Beziehungsknatsch, Alterssymptome und sehr viele Illusionen bestimmen das Schicksal der Männer und Frauen, die zwischen Heimat und Fremde einen sicheren Ort für sich selber suchen. Adolf Jens Koemeda verwebt die Lebensläufe geschickt zu einem weiten Panorama unserer Begierden, Sehnsüchte, Verfehlungen und, selten genug, Erfolge. Als Psychiater versteht er sich auf die leisen Zwischentöne, wobei trotz viel Verständnis und Humor auch das Schrille und Bedrohliche nie verleugnet wird.

\section{«Schurrs Aufbruch» von Alfred Bollinger}

Der emeritierte Gefässspezialist des Zürcher Universitätsspitals hat den Erfinder des Ballonkatheters persönlich gekannt. Das erste Drittel seines Romans «Damals» beschreibt kenntnisreich die Basteleien auf dem später legendären Küchentisch, wo mit Hilfe von Ehefrau und Freunden in unzähligen Nachtstunden die ersten tauglichen Gefässkatheter zusammengebastelt wurden. Die Weg- beschreibung bis zur erfolgreichen Erstdilatation einer Koronararterie 1974 wird mit viel Insiderwissen nacherzählt. Die folgenden Abschnitte, überschrieben mit «Wende» und «Jetzt» schildern die Klinikjahre in den USA, gefolgt von der literarischfiktiven Verleihung des Nobelpreises und dem beruflichen Ausstieg, verbunden mit einer Odyssee durch Südamerika. Der wahre Andreas Grüntzig starb 1985 bei einem Flugzeugabsturz in seiner Privatmaschine, der Autor bereitet ihm im Kantonsspital St. Gallen das Ende durch einen Herzinfarkt. Tatsache ist, dass dem erfolgreichen Erfinder in Zürich weder Patientenbetten noch eine Sekretärin bewilligt wurden, dass er auch in Deutschland keine Professur erhielt, aber in den USA hochwillkommen war, wo ihm eine ganze Klinik zur Verfügung stand. Vielleicht wollte Alfred Bollinger aus Rücksicht auf ehemalige Kollegen nicht von den Machenschaften und Revierkämpfen berichten, die den begabten Mediziner aus Seldwyla vertrieben. Interessiert hätte es schon. 